palate. On attempting to swallow he was unable to raise the tongue from the floor of the mouth, to which it had become firmly adherent. The tongue could be protruded slightly, and it then deviated markedly to the right. No enlarged glands could be felt either under the jaw or in the neck, but there seemed to be a fulness beneath the right angle of the jaw. He complained of no pain in the mouth except when taking food, but occasionally he experienced a sharp pain in the right ear. The other organs of the body were healthy. On March 26 th the patient was anæsthetised, at first with the A.C.E. mixture and subsequently with chloroform by means of a Junker's inhaler. A gag was introduced on the left side by which the mouth was forcibly opened, and the tongue was transfixed near its apex by a stont silk ligature, by which it was drawn as far out cf the mouth as possible. By means of a scalpel the right cheek was cut through in a line with the mouth as far back as the wisdom tooth. Mr. Davies-Colley then snipped away with the scissors all the affected part of the gum, the anterior pillar of the fauces, the right tonsil and part of the soft palate, and finally, by a somewhat oblique incision, practically the whole of the tongue was removed. There was very little bleeding. The cut edges of the mucous membrane were approximated by salmon-gut sutures and the margins of the incision through the cheek were joined by means of a button suture. The patient bore the operation well. A mouth-wash of a solution of resorcin, ten grains to the ounce, with a drachm of glycerine, was used. He was fed by nutrient enemata, and also took a little milk by the mouth. His recovery from the operation was rapid and uneventful, and on April 1st the button suture was removed. At no time after the operation did he complain of any pain, and at an early date he took all his nourishment by the mouth. On April 12th he was practically well.

Remarks by Mr. DAVIES.COLLEY.-This case of epithelioma of the tongue is interesting on account of the great extent of that organ as well as of the soft palate and right tonsil involved without any perceptible enlargement of the lymphatics. I thought, therefore, that I was justified in removing the disease through the mouth by Whitehead's operation. I did not find it necessary to perform laryngotomy, and very little blood got into the air passages, although the section of the dorsum of the tongue on the right side came near to the epiglottis.

\section{GREAT YARMOUTH HOSPITAL.}

A CASE OF VERY EXTENSIVE FRACTURE OF THE BASE OF THE SKULL; NECROPSY.

(Under the care of Dr. H. BLAKE)

THE extensive fracture of the base of the skull which was found post mortem in this case is somewhat unusual from a blow on the occiput. A circular fracture of the base sur. rounding the foramen magnum is by no means rare when resulting from a fall on the vertex, for then the occipital condyles and the adjacent portions of bone are driven into the skull by the momentum of the body acting through the cervical vertebræ. The ecchymoses seen over the mastoid processes are recognised as a trustworthy sign of fracture of the posterior fossa. For the notes of this case we are indebted to Dr. K. W. Monsarrat, house surgeon.

A man, aged fifty years, was admitted to the Gre Hospital on June 2nd, 1896, with a history of having received a blow on the back of the bead by a fall which brought it in contact with the kerbstone. He was intoxicated at the time. When admitted he was unconscious, the breathing was stertorous, and there was free hæmorrhage from both ears. The pupils were contracted and equal, both reacting to light; there was a slight conjunctival reflex. Over the occipital bone on a level with the protuberance, and rather more to the left than the right of the middle line, was a large bruise, but there was no other mark of external violence. On the night of the $2 \mathrm{nd}$ he developed a condition of great irritability and restlessness, so that he had to be tied down in bed. The struggling was noticed to be much more marked on the right side of the body than on the left. He continued in this state until he died, except that on half a dozen occasions, all at night, he asked rational questions as to why he was tied down, \&c.; as a general rule, however, he lay struggling and muttering. On the night of the 7 th he had two general convulsions without any localising symptoms. At midnight on the 8 th he died.

Necropsy. - The post-mortem examination was made seventeen hours after death, and the following are the notes of interest. There was a distinct flattening of the skull about the region of the external occipital protuberance over an area three inches in diameter; there was no ecchymosis there, but behind each ear over the mastoid there was a distinct bruise. On removing the skull-cap there was found an extensive sub-dural hæmorrhage over the left parietal region, without appreciable flattening of the convolutions. There were also small punctiform hæmorrhages over the right occipital and parietal and the left occipital areas of the cortex. Both frontal lobes were lacerated at their anterior extremities, and there was a considerable amount of clot in their torn substance, especially on the left side; there was also a large clot in the substance of the anterior extremity of the left temporo-sphenoidal lobe and in the central part of the left middle temporo-sphenoidal convolution. On removing the brain there was seen to be a fracture commencing at the torcular Herophili and extending outwards on each side to the junction of the petrous and squamous portions of the temporal. Each petrous bone was fractured in several directions, and the line thence extended to meet its fellow of the opposite side on the sella turcica, the posterior clinoid processes being chipped off and loose. The line of fracture was thus completed round the foramen magnum, and was fourteen inches in extent. The skull was of the usual density and thickness.

\section{adtovical Sorretis.}

\section{PATHOLOGICAL SOCIETY OF LONDON,}

Lymphxdenomatosis of the Bones.-Dermatitis Maligna.Bodies in the Vermiform Appendix.-Rupture of the Heart.-Mucosal Cysts.-Gumma of the Epleen.

A MEETING of this society was held on May 4th, the President, Mr. ButrIN, being in the chair.

Dr. F. PARKes WEBER showed specimens of General Lymphadenomatosis of the Bones from a man aged sixty-one years. He complained of pains in different parts of the body, and notably of bilateral abdominal pains, usually worse when he stood up. His spinal column was kept xigidly fixed; there was kyphosis, which appeared to be progressive; and he walked slowly and carefully with the aid of a stick. A little variable cdema over part of the spinal column and one lower extremity was noticed. His appetite was good and he bad no fever, yet he became gradually weaker, and looked more like a man of eighty than one of sixty-one years. His actual death resulted from an asthenic ty pe of pneumonia in both lungs. At the necropsy all the bones which were examined (including all the vertebı $x$ and ribs, the clavicles, and the calvarium) were found more or less affected with the disease. A very vascular, small round-celled growth occupied the centre of the bones and partially replaced the osseous tissue. In some localities the growth was only covered by periosteum, all the osseous tissue beneath it having been absorbed. Portions of the ribs were bulged owing to distension by the rapidly growing neoplasm in their interior. There were some enlarged lymph glands under the right clavicle; these were apparently the site of a similar, but less vascular, growth. The kidneys showed a moderate amount of interstitial change, and in two white specks below the capsule minute, concentrically marked calculi could be seen with the microscope. These, Mr. Shattock ascertained, consisted of phosphates. The lungs showed greyish consolidation at both bases. Part of the consolidated lung was examined microscopically and presented a peculiar homogeneous hyaline appearance of the material between the cells. Unfortunately in the present case no examination of the blood was made. Dr. Weber thought that his case was of the same nature as those variously described as "multiple myeloma," "medullary pseudo-leukæmia," "myelogenic leukæmia," "pernicious anæmia with associated affection of bone marrow," and " primary sarcomatous osteitis." --The PRESIDENT said that in a case which he exhibited before the society in 1879 there were definite myeloid tumours. The existence of any disease had not been suspected until the 